\title{
Post Nipple-Sparing Mastectomy Reconstruction: Renewed Popularity of Latissimus Dorsi Flap for More Cosmetically Appealing Results
}

\author{
MOHAMED A. WAHSH, M.D. \\ The Department of General Surgery, Plastic \& Reconstructive Surgery Unit, Faculty of Medicine, Zagazig University
}

\begin{abstract}
Background: Breast reconstruction became a dynamic continually progressing group of procedures. These procedures are aiming to provide the patients after mastectomy more symmetrical and an aesthetically pleasing recreated breast in the cases which are fulfilling multiple basic oncologic goals. The reconstruction must not impede the oncological safety or cause a delay in detection of local recurrence or adjuvant cancer management. The aim of the current study is to evaluate the surgical outcomes of the immediate breast reconstruction by latissimus dorsi flap in patients after nipple sparing mastectomy regarding the aesthetic results, post-operative complications and patient satisfaction.
\end{abstract}

Patients and Methods: Eight consecutive patients having invasive breast cancer ( 7 patient have invasive duct carcinoma and a patient has invasive lobular carcinoma) underwent nipple sparing mastectomy. All patients had immediate breast reconstruction by latissimus dorsi flap at Zagazig University hospitals within three years. Surgical outcomes in terms of post-operative complications including hematoma, wound infection, scarring, dorsal seroma, skin necrosis, back pain, and aesthetic outcomes such as breast symmetry, visual difference of bilateral breasts, breast contour, and nipple cosmoses were assessed.

Results: Surgical outcomes including post-operative complications; hematoma, wound infection were not detected. Marked back scarring (25\%), dorsal seroma (12.5\%) were reported. Aesthetic outcomes were satisfactory and $75 \%$ of patients reported excellent satisfaction with (2 cases) $25 \%$ were not satisfied due to the back scar or volume asymmetry.

Conclusion: Following nipple sparing mastectomy, purely autogenous immediate breast reconstruction by latissimus dorsi flap is a valuable reconstructing technique in selected type of patients. It has low incidence of complications, considerable aesthetic outcomes with high patient satisfaction relieving the psychological postmastectomy trauma.

Key Words: Mastectomy - Post nipple-sparing - Latissimus dorsi flap.

\section{INTRODUCTION}

By restoring body image after mastectomy, breast reconstruction improves the overall selfesteem, satisfaction, sexuality, and quality of life after surgery. Also, it has proofed to alleviate the post mastectomy depression and anxiety [1-5].
Breast reconstruction became a dynamic continually progressing group of procedures. These procedures are aiming to provide the patients after mastectomy more symmetrical and an aesthetically pleasing recreated breast in the cases which are fulfilling multiple basic oncologic goals. The reconstruction must not impede the oncological safety or cause a delay in detection of local recurrence or adjuvant cancer management [6-9].

Autogenous, non-autogenous and combined modalities have been used in breast reconstruction with dramatic improvement over the last decades. By reconstruction with autogenous tissues, it is easier to achieve symmetry without other breast modifications. Also, the autogenous reconstruction has its own indications in multiple situations, including ptotic contralateral breast, previous radiation or previous failed reconstruction by implants $[6,10,11,12]$.

The latissimus dorsi flap was used in breast reconstruction either with or without implants. It presents a common source for autogenous breast reconstruction with the previously mentioned advantages and, in selected cases, it provides a good reconstruction option [13].

Changing the management concepts in breast cancer has motivated the breast reconstruction surgeons to follow more developed techniques seeking more aesthetic outcome and less complications.

With growing the popularity of skin -sparing mastectomy, the glandular tissue and nipple areola complex are removed while the breast envelope is maintained which enhances the reconstruction greatly. The preservation of intermammary crease, inframammary fold and breast envelope keeps the breast anatomical cornerstones. Hence, it helps the plastic surgeon to achieve more natural results 
with preservation of these complicated anatomical structures $[\mathbf{9 , 1 4}]$.

Several studies have concerned with the risk of local recurrence in skin sparing mastectomy and concluded to have a comparable risk with modified radical mastectomy i.e. 5.8\% in early stages (stage one and two) [15] However, there is an increased risk of local recurrences i.e. $31 \%$ in stage III and more advanced cases $[\mathbf{1 5 , 1 6 ]}$.

Further modification has occurred in nipplesparing mastectomy with preservation of nippleareola complex with the breast skin envelope and removal of the glandular tissue [14]. This technique has a significant concern of nipple necrosis that may exceed $10 \%$ which is assumed to be related to the site of incision. Also, this technique has the risk of local recurrence which occurs usually in multicenteric lesions and subareolar tumours. $[\mathbf{1 7 , 1 8 , 1 9 ]}$. However, in one study, the local recurrences with nipple sparing technique were three cases in 123 cases none of them were in nippleareola complex [18]. Nonetheless, it is a promising technique with high over all patient satisfaction [18] Also, longer follow-up periods and larger sample size reported low recurrence risks [20,21].

The patient with peripheral lesions not less than $2 \mathrm{~cm}$ from the areolar edge and the lesion is small and unicenteric can usually be offered this option. Intra operative frozen section examination is preferred to roll out occult malignant cells in the nipple areola complex. Also, the patient should be informed that there is still lack of high quality data of the oncologic safety of the nipple sparing mastectomy. The patient also should be consented that the nipple areola complex may be insensate, has a post-operative necrosis or be scarified intraoperatively if the tumour found proximal to it [21].

Although breast reconstruction can change the life style of the patient, it has its associated risk and complications which are continually studied to be minimized and to enhance the surgery of breast reconstruction [10].

The aim of the current study is to evaluate the surgical outcomes of the immediate breast reconstruction by latissimus dorsi flap in patients after nipple sparing mastectomy regarding the aesthetic results, post-operative complications and patient satisfaction.

\section{PATIENTS AND METHODS}

Eight consecutive patients having invasive breast cancer ( 7 patient have invasive duct carci- noma and a patient has invasive lobular carcinoma) underwent nipple sparing mastectomy. All patients had immediate breast reconstruction by latissimus dorsi flap at Zagazig University Hospitals within three years.

\section{Patient selection:}

Eight patients with breast cancer were included having stage 1 and 2 unicenteric tumors according to TNM staging; American Joint Committee on Cancer (AJCC) system. The degree of patient satisfaction was estimated by a survey (poor, fair, good, and excellent) in post-operative follow-up visits (range, 13 to 21 months). Written informed consent for the study inclusion and publication was obtained from the patients. All these patients received immediate breast reconstruction using pedicled latissimus dorssi flap.

\section{Exclusion criteria:}

Patients with tumour size more than $2 \mathrm{~cm}$., multicenteric tumours, subearolar tumours, tumours with skin involvements or with the tumour to nipple distance less than $4 \mathrm{~cm}$. and patients with breast size cup D or larger were excluded from the study.

\section{Surgical procedure:}

Nipple sparing mastectomy with axillary lymph node dissection were performed using a lateral transverse breast incision (3 cases), lateral inframammary incision ( 3 cases), elliptical excising of the previous biopsy scar (1 case; Fig. 1a) or elliptical excising of skin when the tumor was close to the skin. (1 case). In the breast, careful dissection in the plane of the superficial layer of the superficial fascia with preservation of the inframammary fold should be done. (Fig. 1d).

Through the anterior approach, the identification of the anterior part of the latissimus dorsi muscle and the thoracodorsal vessels was performed after completion of NSM. Afterwards, the latissimus dorsi flap has been harvested on thoracodorsal neurovascular pedicle after the patient was turned to the lateral decubitus position, and skin incision was made within the posterior axillay line (4 cases) or within the brassière line (4 cases). A subcutaneous tunnel between the mastectomy defect and the donor site was done and the flap was elevated and transferred to the mastectomy defect (Fig. 2d). Two or more closed suction drains were left at the LD donor site, mastectomy defect and axilla. These drains were removed when the daily output became less than $30 \mathrm{cc}$.

Surgical outcomes in terms of post-operative complications including hematoma, wound infec- 
tion, scarring, dorsal seroma, skin necrosis, back pain, and aesthetic outcomes such as breast symmetry, visual difference of bilateral breasts, breast contour, and nipple cosmoses were assessed by a panel of three judges (operating surgeon and other two colleagues of surgeons).
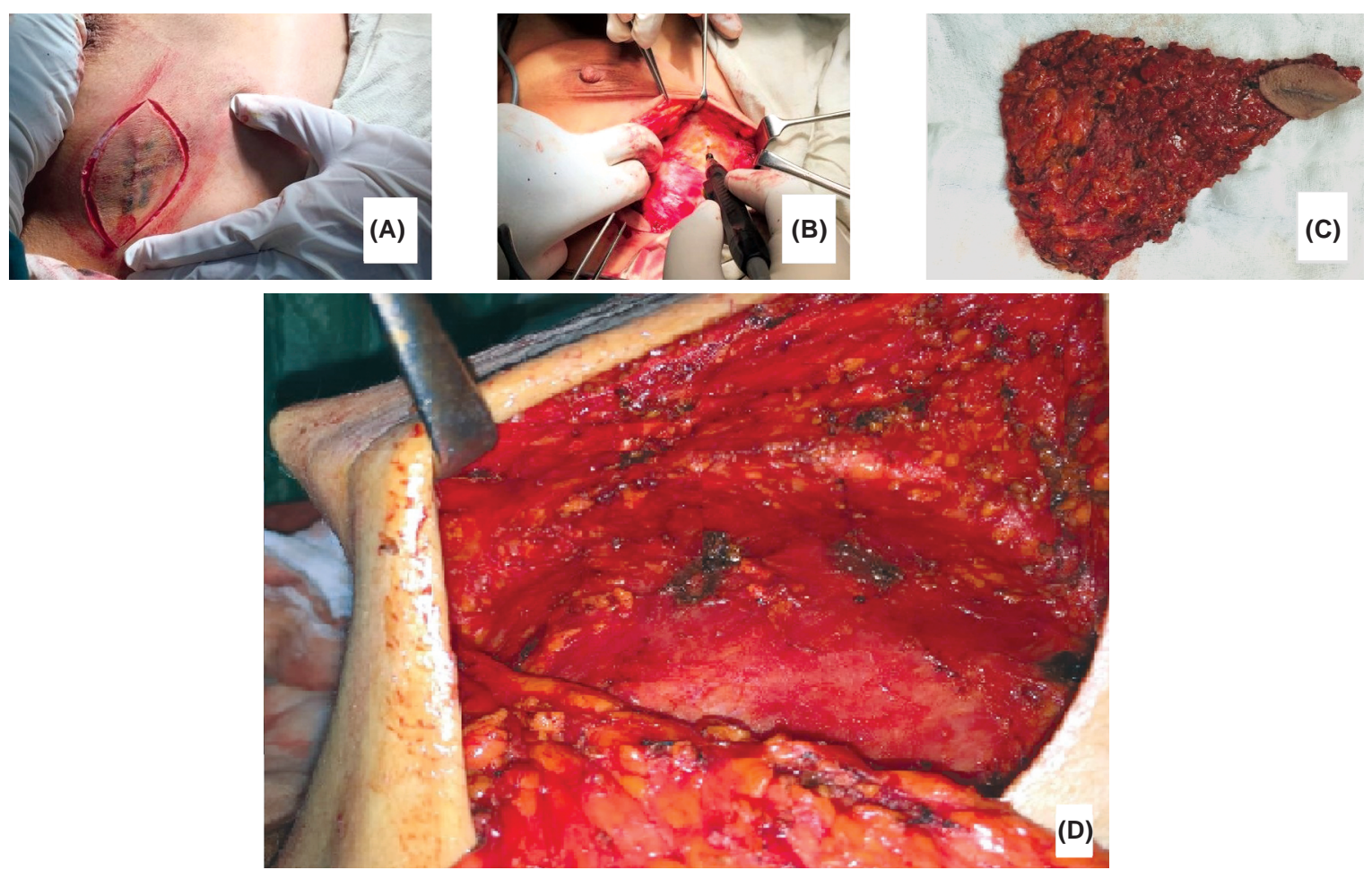

Fig. (1): Nipple sparing mastectomy (A): Incision was replaced by elliptical excision of the large previous biopsy scar, (B): Nipple sparing mastectomy with glandular resection in the superficial layer of superficial fascia; axillary clearance was done also through this opening, (C): The mastectomy specimen, (D): Internal view after mastectomy.

Flap Tunneling
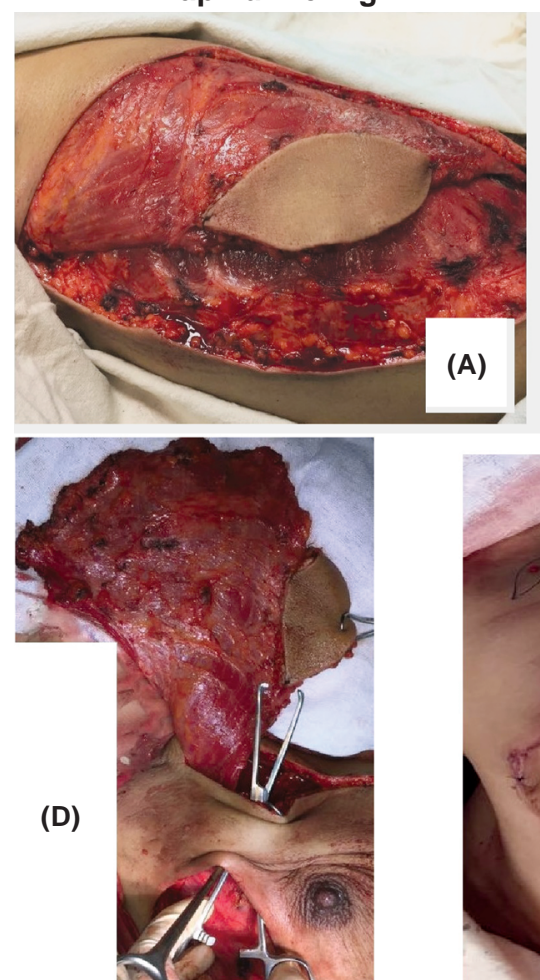

Flap Tunneling

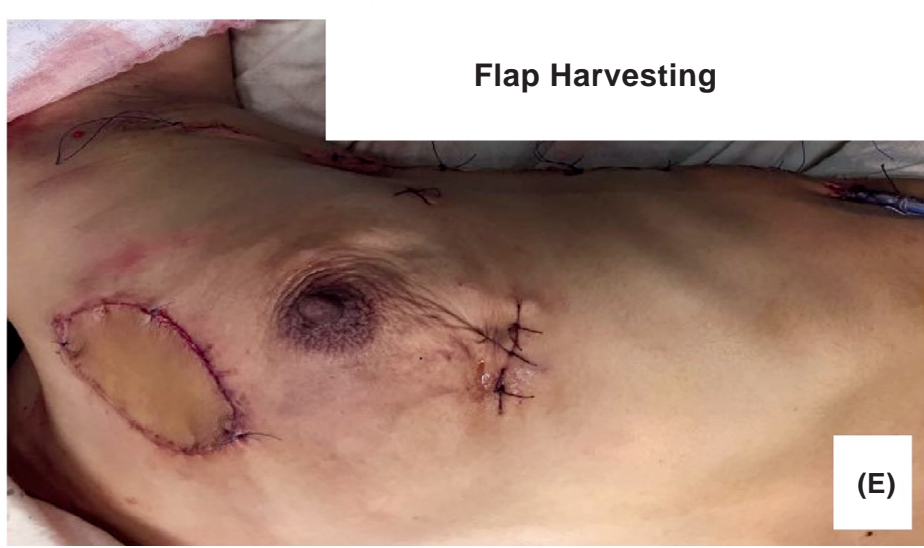

Flap Insetting

Fig. (2): Breast reconstruction with latissimus dorsi flap (A,B,C): Flap harvesting, (D): Flap tunneling, (E): Flap insetting with fixation to the inframammary line by 2 subcutaneous sutures. 


\section{RESULTS}

Eight patients underwent NSM and immediate purely autogenous breast reconstruction with latissimus dorsi flap. The mean age of the patients was 48.4 years (range, 24 to 48 ). In 7 patients $(85.5 \%)$ the pathological results were: Infiltrating ductal carcinoma and in one patient $(12.5 \% \%)$ the result was infiltrating lobular carcinoma. The mean tumor size was $17 \mathrm{~mm}$ (range, 12 to $20 \mathrm{~mm}$ ). After a mean follow-up period of 17 months (range, 13 to 21 months), none of the patients developed local recurrence. Only 1 patient (12.5\%) developed an axillary metastasis, and the overall patient survival was $100 \%$ (Table 1 ).

Table (1): Study population characteristics.

\begin{tabular}{ll}
\hline \multicolumn{1}{c}{ Cases $\mathrm{n}$} & \multicolumn{1}{c}{$(\mathrm{n}=8)$} \\
\hline Age, years & $\begin{array}{l}\text { Mean 48.4 years } \\
\text { (range, 24 to 48) }\end{array}$ \\
Follow-up, months & Mean 17 months \\
& (range, 13 to 21) \\
Pathological examination: & \\
Infiltrating ductal carcinoma & 7 \\
Infiltrating lobular carcinoma & 1 \\
Tumor size, mm & $17 \mathrm{~mm}$ \\
& $($ range, 12 to 20mm) \\
Stage: & \\
I & 2 \\
IIA & 3 \\
IIB & 3 \\
Local recurrence & 0 \\
\hline
\end{tabular}

\section{Post-operative complications:}

Post-operative complications including hematoma, wound infection, flap complications, marked scarring, dorsal seroma, skin necrosis and back pain were reported. The incidence of hematoma $0 \%$, wound infection $0 \%$, and skin flap necrosis $0 \%$. Donor site morbidities occurred in 2 cases; dorsal seroma occurred in one (12.5\%) which was managed with repeated percutaneous aspiration. Marked scarring occurred in $2(25 \% \%)$, and back pain in $0(0 \%)$.
Table (2): Post-operative complications.

\begin{tabular}{ll}
\hline & $(\mathrm{n}=8)$ \\
\hline Hematoma & 0 \\
Wound infection & 0 \\
Necrotic nipple or breast & 0 \\
$\quad$ skin complications & \\
Flap complications & 0 \\
Skin necrosis & 0 \\
Flap loss & 0 \\
Donor site morbidity: & \\
$\quad$ Marked scarring & $2(25 \%)$ \\
$\quad$ Seroma & $1(12.5 \%)$ \\
$\quad$ Back pain & 0 \\
\hline
\end{tabular}

\section{Aesthetic outcomes:}

The aesthetic outcomes were assessed by a panel of three judges (operating surgeon and other two colleagues of surgeons) using a score one to five. These patients were reviewed according to the breast aesthetic characters in the form of the breast shape, size, contour, projection, ptosis, scarring and visual symmetry. The nipple areola complex (NAC) was reviewed according to the transverse level, vertical location and dimensions of NAC, nipple direction and the nipple necrotic complications. Other complications of the breast or donor site were also reported.

Table (3): Aesthetic outcomes.

\begin{tabular}{lll}
\hline Aesthetic scoring & Mean & Range 1 to 5 \\
\hline Breast Mound: & & \\
$\quad$ Shape & 4.3 & $(3$ to 5) \\
Size & 4,2 & $(3$ to 5) \\
Contour & 4.2 & $(4$ to 5) \\
Projection & 4 & $(4$ to 5) \\
Ptosis & 3.7 & $(4$ to 5) \\
Scarring & 4.6 & $(4$ to 5) \\
Visual symmetry & 4.2 & $(3$ to 5$)$ \\
Nipple areola complex: & & \\
Transverse level & 3.8 & $(3$ to 5) \\
$\quad$ Vertical location & 4.4 & $(4$ to 5) \\
Dimensions symmetry & 4.3 & $(4$ to 5) \\
Nipple direction & 4.1 & $(3$ to 5) \\
\hline
\end{tabular}

A survey for estimation of patient satisfaction was reported for all cases in the follow-up visits. Six patients have reported an excellent satisfaction and two patients were unsatisfied. The two poorly satisfied patients have denoted the causes due to back incision and relatively smaller breast mound. 

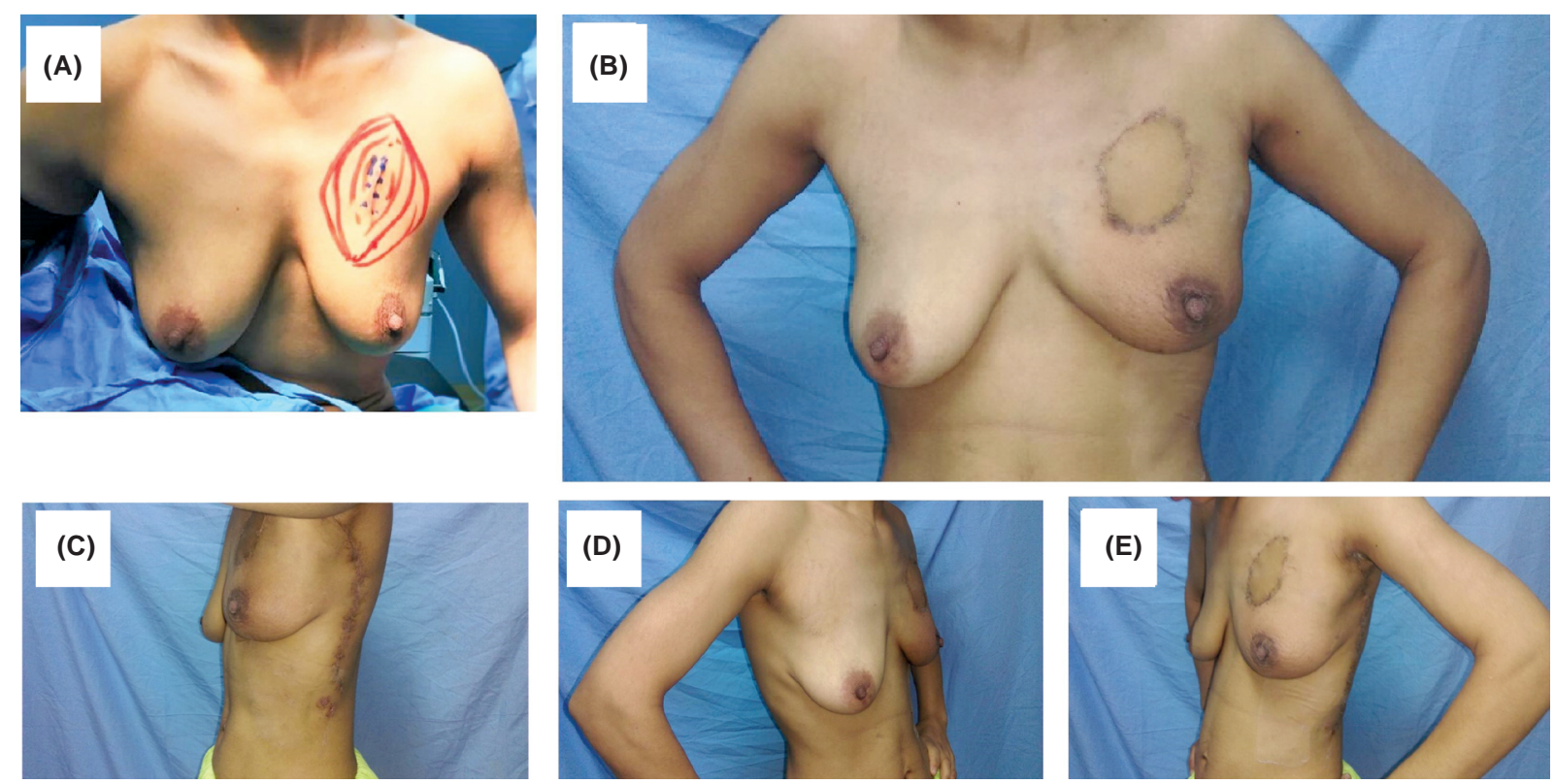

Fig. (3): Before and after reconstruction views of 36 years old patient with infiltrating duct carcinoma, (A): Pre-operative view, (B): Post-operative view with the island of skin of myocutaneous latissimus dorsi flap to compensate the excised skin around the previous biopsy scar, (C): Anterolateral view with the donor site scar, (D,E): Right and left anterolateral view.

\section{DISCUSSION}

Management of breast cancer with advanced surgical modalities resulted in continuous modifications in breast reconstruction which became an integral part in the management of these cases. Even with these dynamic advancements, sparing the oncological safety without delaying the adjuvant cancer management has its priority in the breast reconstruction. The main aesthetic goals of the reconstruction are to restore the breast shape, contour, projection, optimal symmetry, with the least complications of the breast or donor site $[6,7]$.

In the current study, eight patients underwent NSM with immediate breast reconstruction by latissimus dorsi flap. These patients were reviewed according to the breast aesthetic characters in the form of the breast shape, size, contour, projection, ptosis, scarring and visual symmetry. The nipple areola complex (NAC) was reviewed according to the transverse level, vertical location and dimensions of NAC, nipple direction and the nipple necrotic complications. Other complications of the breast or donor site were also reported.

Barton and his colleagues [22], concluded that no grantee of complete malignant cells clearance with increasing the radicality of the mastectomy surgery. Residual glandular tissue was reported in $5 \%$ of biopsies taken from patients after conventional modified radical mastectomy. Also, Ho et al., [23] have reported that the skin flaps contains malignant cells in up to $23 \%$ of cases. The local recurrence within the skin flap in a large systemic review in about 3 years follow-up period was $0.9 \%$ and $4.2 \%$ in skin sparing mastectomy far lower than what had reported in unicenteric studies [23].

A debate has been arisen if leaving the nipple areola complex may result in adding other site for local tumour recurrence. In a study included 934 patients operated for nipple sparing mastectomy, the local recurrence in nipple areola complex were $0.8 \%$ in $3.5 \%$ detected recurrences in breast invasive duct carcinoma and $2.9 \%$ recurrence rate in $4.9 \%$ of cases with intra epithelial breast cancers within fifteen months follow-up period [25]. In 2013, Sakurai and his coauthors in a comparable study did not found any significant difference in disease free survival or the overall survival between patients of NSM and the conventional mastectomy [26]. With this comparable oncological safety, the sparing of these important structures could be achievable. So, in nipple sparing mastectomy with preservation of the breast envelope, inframammary fold and nipple areola complex, the breast reconstruction acquires a great cosmetic opportunity.

The tumour size in this study were less than 2 $\mathrm{cm}$. Although the tumour size has been the most important factor in selection of the patients who are candidates for NSM, Agarwal et al., [27] reported increasing incidences in the studies of sizes larger than $2 \mathrm{~cm}$ with increasing confidence of the technique. Furthermore, Leclere et al., [28] used NSM 
technique for 18 in 42 cases with more than $3 \mathrm{~cm}$ tumour size with $5.3 \%$ local recurrence rate.

The distance between the tumour to nipple in the inclusion critera of the present study was at least $4 \mathrm{~cm}$. In consistence with the current study, Chattopadhyay et al., [29] in 2014 reported 0\% local recurrence rate in NSM patients when the tumour to nipple median distance was $3.8 \mathrm{~cm}$. In the other hand, Fortunato et al., [30] found less than $1 \%$ recurrence rate within 26 months followup periods in series of cases with $65 \%$ of tumour to nipple distances were less than one $\mathrm{cm}$. The result of Fortunato et al., suggested that the previous guidelines regarding that the tumour to nipple distance must exceed $2 \mathrm{~cm}$ should be reviewed. Other selection parameters were suggested to be used for careful patient selection in NSM patients like pre-operative MRI imaging [31] or intraoperative retroareolar frozen section [17] study.

Subareolar tumours were an excluded from the current study which is consistent with a study by Eisenberg and his colleagues [32] as they confirmed that centrally located breast cancers have significant nipple margin involvement and this location is associated by NAC malignant cells involvement in $40 \%$ of cases. The tumour location in the present study was generally evaluated by clinical examination but MRI imaging were needed twice in doubtful cases. In consistency, Moon et al., [31] has reported a positive correlation between NAC enhancement and malignant invasion with high sensitivity and specificity.

In the current study, the benefits of immediate breast reconstruction have been revealed in minimizing the hospital admissions and stages of surgeries as well relieving the postmastectomy psychological trauma. This conclusion was reported by many authors [32].

The breast reconstruction using autogenous tissue has its own indications in multiple situations, including [10] ptotic contralateral breast, previous radiation or previous failed reconstruction by implants [6]. The latissimus dorsi flap was used in breast reconstruction either with or without implants. It presents a common source for autogenous breast reconstruction with the previously mentioned advantages and, in selected cases, it provides a good reconstruction option $[\mathbf{6}, \mathbf{1 1}, \mathbf{1 2}]$.

The flap has been reported as a good option in reconstructing patients with failed previous reconstruction or previous abdominal surgeries $[\mathbf{6 , 1 2}]$.

In the other hand, the volume of the reconstructed breast created from the flap only is relatively small which should be considered. So, achieving symmetrical results usually occurs either by selection of patients with suitable breast mound, using the flap with autogenous augmenting tissues or to use the flap associated with an implant. In the current study, the patients included are with cup $\mathrm{A}, \mathrm{B}$ or $\mathrm{C}$ breast sizes. Also, near total flap use and inclusion of the latissimus dorsi muscle overlying fat to obtain an extra volume were performed. Some studies reported the use of the latissimus dorsi overlying fat in the series of McCrew and Papp [34]. Also, Denewer [13] created the extra volume by using the fat overlying the serrstus anterior muscle as a pedicled flap.

The purely autogenous reconstructions in the present study avoided the complications associated with using implants such as capsular contracture, delayed healing, implant malposition, implant extrusion or infection. In the other hand, the latissimus dorsi breast reconstruction still carried the risk of donor site morbidities, seroma formation (47\%-96\%), back contour irregularity and shoulder weakness which reported in the study of Sigurdson et al., [36] In the current study, the incidence of seroma was significantly lower; $25 \%$ without detection of noticed shoulder function disabilities. An important drawback of the procedure in the present study was the noticed back scar which was alleviated to some extent by orienting the incision transversely in the brassiere line, careful subcuticular skin closure and post-operative wound care.

Rawlani et al., [33] reported in their study that a higher rate of nipple necrosis was associated with the periareolar incision than using the lateral or inframammary incision in NSM. Regarding the current study, medial breast incisions were avoided instead lateral or lateral inframammary incision were used in NSM. Also, Crowe et al., [37] supported this attitude and reported that the medial incisions may compromise the nipple blood supply. In two cases, when a previous biopsy was taken before with large incision, an ellipse of the skin surrounding the previous scar were excised and used for NSM and the defect is replaced by a skin paddle of the back as a myocutaneous latissimus dorsi flap with good colour match. No necrotic complications were reports in the cases of the present study this may be due to the use of these incisions and not the periareolar and the relatively small breast mounds included in the study. In consistence with this concept Colwell and his colleagues have linked increasing nipple necrosis incidence with obesity or with a large breast volume [38]. 
Regarding different studies, the necrotic complications still have relatively low rates ranging from $3.5 \%$ in total nipple necrosis to $12.1 \%$ in partial nipple necrosis and NSM is still a useful technique [38-41]. Furthermore, Alperovich et al., [42] have argued that the necrotic complications with NSM has not increased with subsequent radiotherapy if needed.

In terms of nipple sensation, six cases in the current study have been preserved. Nahabedian and Tsangaris [43] reported that NSM has maintained sensation in 6 of 14 nipples $(42.9 \%)$. The nerve supply to the nipple from the lateral T4 is scarified in most mastectomies. However, a part of NAC innervation comes from medial T3 which is responsible for nipple sensation preservations in these cases [44]. The higher incidence of preserving nipple sensibility in the present study may be due to the selection lateral and lateral inframammary incisions and avoidance of medial incisions with preservation of these innervation.

In the present study, After NSM and immediate latissimus dorsi breast reconstruction, a survey for estimation of patient satisfaction was reported for all cases in the follow-up visits. Six patients have reported an excellent satisfaction and two patients were unsatisfied. The two poorly satisfied patients have denoted the causes due to back incision and relatively smaller breast mound. This result was comparable with the result of Nahabedian and Tsangaris [43] who obtained patient satisfaction in 11 of 14 patients $(78.6 \%)$.

\section{Conclusion and recommendations:}

Following nipple sparing mastectomy, purely autogenous immediate breast reconstruction by latissimus dorsi flap is a valuable reconstructing technique in selected type of patients. It has low incidence of complications, considerable aesthetic outcomes with high patient satisfaction relieving the psychological postmastectomy trauma. Further researches in terms of more volume enlargement and minimizing donor scar effects could preserve the privileges of latissimus dorsi breast reconstruction in nipple sparing mastectomy patients, maximize its use in breast reconstruction and expand the spectrum to a larger group of patients.

\section{REFERENCES}

1- Fernández-Frías A.M., Aguilar J., Sánchez J.A., Merck B., Piñero A. and Calpena R.: Immediate reconstruction after mastectomy for breast cancer: Which factors affect its course and final outcome? J. Am. Coll. Surg., 208: 126-133. [Pub. Med.], 2009.

2- Reuben B.C., Manwaring J. and Neumayer L.A.: Recent trends and predictors in immediate breast reconstruction after mastectomy in the United States. Am. J. Surg., 198: 237-243. [Pub. Med.], 2009.

3- Panieri E., Lazarus D., Dent D.M., Hudson D.A., Murray E. and Werner I.D.: A study of the patient factors affecting reconstruction after mastectomy for breast carcinoma. Am. Surg., 69: 95-97, [Pub. Med.], 2003.

4- Al-Ghazal S.K., Sully L., Fallowfield L., et al.: The psychological impact of immediate rather than delayed breast reconstruction. Eur. J. Surg. Oncol., 26: 17-19. [Pub. Med.], 2000.

5- Knottenbelt A., Spauwen P.H.M. and Wobbes T.H.: The oncological implications of immediate breast reconstruction. Eur. J. Surg. Oncol., 30: 829-833. [Pub. Med.], 2004.

6- Losee J.E. and Gimbel M.: Plastic and Reconstructive Surgery: Schwartz's Principles of Surgery. New York, NY: McGraw Hill, 2010.

7- Dunnington G., Andriole D. and Kaiser S.: Breast Essentials of General Surgery. Philadelphia, P.A.: Lippincott; 2006.

8- Harcourt D.M., Ramsey N.J., Ambler N.R., et al.: The psychological effect of mastectomy with or without breast reconstruction: A prospective, multi-center study. Plast. Reconstr. Surg., 111: 1060-1068. [Pub. Med.], 2003.

9- Choi J.Y., Alderman A.K. and Newman LA.: Aesthetic and reconstructive considerations in oncologic breast surgery. J. Am. Coll. Surg., 202: 943-944. [Pub. Med.], 2006.

10- Paul H. Jr1, Prendergast TI2, Nicholson B2, White S2, and Frederick W.A.: Breast reconstruction: Current and future options. Breast Cancer (Dove Med. Press). Aug., 17 (3): 93-9. doi: 10.2147/BCTT.S13418, 2011.

11- Abdalla H.M., Shalaan M.A., Fouad F.A. and Elsayed A.A.: Immediate breast reconstruction with expander assisted latissimus dorsi flap after skin sparing mastectomy. J. Egypt Natl. Canc. Inst., 18: 134-140. [Pub. Med.], 2006.

12- Townsend C.M. Jr, Beauchamp R.D., Evers B.M., Mattox K.L., editors: Sabiston Textbook Of Surgery: The Biological Basis of Modern Surgical Practice. 18 th ed. Philadelphia, P.A.: W.B. Saunders, 2008.

13- Denewer A. and Farouk O.: Can nipple-sparing mastectomy and immediate breast reconstruction with modified extended latissimus dorsi muscular flap improve the cosmetic and functional outcome among patients with breast carcinoma? World. J. Surg., 31: 1169-1177. [Pub. Med.], 2007.

14- Reefy S., Patani N., Anderson A., Burgoyne G., Osman H. and Mokbel K.: Oncological outcome and patient satisfaction with skin-sparing mastectomy and immediate breast reconstruction: A prospective observational study. BMC Cancer., 10: 171. [PMC free article] [Pub. Med.], 2010.

15- Greenway R.M., Schlossberg L. and Dooley W.C.: Fifteenyear series of skin sparing mastectomy for stage 0 to 2 breast cancer. Am. J. Surg., 190: 918-922. [Pub. Med.], 2005.

16- Medina-Franco H., Vasconez L.O., Fix R.J., et al.: Factors associated with local recurrence after skin-sparing mastectomy and immediate breast reconstruction for invasive breast cancer. Ann. Surg., 235: 814-819. [PMC free article] [Pub. Med.], 2002. 
17- Sacchini V., Pinotti J.A., Barros A.C., et al.: Nipplesparing mastectomy for breast cancer and risk reduction: Oncologic or technical problem. J. Am. Coll. Surg., 203: 704-714. [Pub. Med.], 2006.

18- Wijayanayagam A., Kumar A.S., Foster R.D. and Esserman L.J.: Optimising the total skin sparing mastectomy. Arch. Surg., 143: 38-45. [Pub. Med.], 2008.

19- Simmons R.M., Brennan M., Christos P., King V. and Osborne M.: Analysis of nipple/areolar involvement with mastectomy: can the areola be preserved. Ann. Surg. Oncol., 9: 165-168, 2002.

20- Sakamoto N., Fukuma E., Higa K., et al.: Early results of an endoscopic nipple-sparing mastectomy for breast cancer. Ann. Surg. Oncol., 16: 3406-3413, 2009.

21- Gerber B., Krause A., Reimer T., et al.: Skin-sparing mastectomy with conservation of the nipple-areola complex and autologous reconstruction is an oncologically safe procedure. Ann. Surg., 238: 120-127, 2003.

22- Barton F.E. Jr., English J.M., Kingsley W.B., et al.: Glandular excision in total glandular mastectomy and modified radical mastectomy: A comparison. Plast. Reconstr. Surg., 88: 389-392. [Pub. Med.], 1991.

23- Ho C.M., Mak C.K., Lau Y., et al.: Skin involvement in invasive breast carcinoma: Safety of skin-sparing mastectomy. Ann. Surg. Oncol., 10: 102-107. [Pub. Med.], 2003.

24- Mallon P., Feron J.G., Couturaud B., et al.: The role of nipple-sparing mastectomy in breast cancer: A comprehensive review of the literature. Plast Reconstr Surg., 131: 969-984. [Pub. Med.], 2013.

25- Petit J.Y., Veronesi U., Orecchia R., et al.: Risk factors associated with recurrence after nipple-sparing mastectomy for invasive and intraepithelial neoplasia. Ann. Oncol., 23: 2053-2058. [Pub. Med.], 2012.

26- Sakurai T., Zhang N., Suzuma T., et al.: Long-term followup of nipple-sparing mastectomy without radiotherapy: A single center study at a Japanese institution. Med. Oncol., 30: 481. [Pub. Med.], 2013.

27- Agarwal S., Neumayer L., et al.: Therapeutic nipplesparing mastectomy: Trends based on a national cancer database. Am. J. Surg., 208: 93-98. [Pub. Med.], 2014.

28- Leclere F.M., Panet-Spallina J., Kolb F., et al.: Nipplesparing mastectomy and immediate reconstruction in ductal carcinoma in situ: A critical assessment with 41 patients. Aesthetic Plast. Surg., 38: 338-343. [Pub. Med.], 2014.

29- Chattopadhyay D., Gupta S., Jash P.K., et al.: Skin sparing mastectomy with preservation of nipple areola complex and immediate breast reconstruction in patients with breast cancer: A single centre prospective study. Plast. Surg. Int., 2014: 589068. [PMC free article] [Pub. Med.], 2014.

30- Fortunato L., Loreti A., Andrich R., et al.: When mastectomy is needed: Is the nipple-sparing procedure a new standard with very few contraindications? J. Surg. Oncol. 108: 207-212. [Pub. Med.], 2013.

31- Moon J.Y., Chang Y.W., Lee E.H., et al.: Malignant invasion of the nipple-areolar complex of the breast: Usefulness of breast MRI. AJR. Am. J. Roentgenol., 201: 448-455. [Pub. Med.], 2013.
32- Eisenberg R.E., Chan J.S., Swistel A.J., et al.: Pathological evaluation of nipple-sparing mastectomies with emphasis on occult nipple involvement: The Weill-Cornell experience with 325 cases. Breast J. 20: 15-21. [Pub. Med.], 2014.

33- Rawlani V., Fiuk J., Johnson S.A., et al.: The effect of incision choice on outcomes of nipple-sparing mastectomy reconstruction. Can. J. Plast. Surg., 19: 129-133. [PMC free article] [Pub. Med.], 2011.

34- McCrew J.B. and Papp C.T.: Latissimus dorsi myocutaneous flap: "Fleur de lis" reconstruction. In CR Hartrampf, editor, Breast Reconstruction with Living Tissue. Norfolk, V.A., Hampton Press 221Google Scholar, 1991.

35- Raafat Y. Afifi and Ali El-Hindawy: Analysis of nippleareolar complex involvement with mastectomy: Can the nipple be preserved in Egyptian patients receiving skinsparing mastectomy? Breast J. 10: 543-545 Google Scholar, 2004

36- Sigurdson L. and Lalonde D.: MOC-PSSM CME article: Breast reconstruction. Plast. Reconstr. Surg., 121: 1-12. [Pub. Med.], 2008.

37- Crowe J.P., Jr, Kim J.A., Yetman R., Banbury J., Patrick R.J. and Baynes D.: Nipple-sparing mastectomy: Technique and results of 54 procedures. Arch. Surg., 139: 14850. [Pub. Med.], 2004.

38- Colwell A.S., Tessler O., Lin A.M., et al.: Breast reconstruction following nipple-sparing mastectomy: Predictors of complications, reconstruction outcomes, and 5-year trends. Plast. Reconstr. Surg., 133: 496-506. [Pub. Med.], 2014.

39- Radovanovic Z., Radovanovic D., Golubovic A., et al.: Early complications after nipple-sparing mastectomy and immediate breast reconstruction with silicone prosthesis: results of 214 procedures. Scand. J. Surg., 99: 115-118. [Pub. Med.], 2010.

40- Munhoz A.M., Aldrighi C.M., Montag E., et al.: Clinical outcomes following nipple-areola-sparing mastectomy with immediate implant-based breast reconstruction: A 12-year experience with an analysis of patient and breastrelated factors for complications. Breast. Cancer. Res. Treat., 140: 545-555. [Pub. Med.], 2013.

41. Chirappapha P., Petit J.Y., Rietjens M., et al.: Nipple sparing mastectomy: does breast morphological factor related to necrotic complications? Plast. Reconstr. Surg. Glob. Open., 2: e99. [PMC free article] [Pub. Med.], 2014.

42- Alperovich M., Choi M., Frey J.D., et al.: Nipple-sparing mastectomy in patients with prior breast irradiation: are patients at higher risk for reconstructive complications? Plast. Reconstr. Surg., 134: 202e-206e. [Pub. Med.], 2014.

43- Nahabedian M.Y. and Tsangaris T.N.: Breast reconstruction following subcutaneous mastectomy for cancer: A critical appraisal of the nipple-areola complex. Plast Reconstr Surg., 117: 1083-1090 Pub. Med. Cross. Ref. Google Scholar, 2006.

44- Laronga C.: Quality of life with skin-sparing mastectomy: Sensation in the nipple-areola complex. J. Support. Oncol., 4: 234-235 Pub. Med. Google Scholar, 2006. 